\title{
Transient Distal Renal Tubular Acidosis in Organophosphate Poisoning
}

\author{
Ram Narayan, Mansoor C. Abdulla, Jemshad Alungal \\ Department of General Medicine, MES Medical College, Perinthalmanna, Kerala, India
}

\section{Abstract}

Renal complications due to organophosphate poisoning are very rare. We are presenting a unique case of transient distal renal tubular acidosis due to organophosphate poisoning, which to the best of our knowledge is the first of its kind. An elderly female after deliberate self-harm with ingestion of chlorpyrifos had multiple ventricular arrhythmias due to hypokalemia secondary to distal renal tubular acidosis which improved completely after treatment.

Keywords: Chlorpyrifos, distal renal tubular acidosis, hypokalemia, organophosphate, ventricular arrhythmias

\section{INTRODUCTION}

Organophosphate poisoning is a ubiquitous problem and is very prevalent in developing countries. Patients commonly present with acute cholinergic crisis, intermediate syndrome, or delayed polyneuropathy. They may also present with pancreatitis or hepatitis. ${ }^{[1]}$ Here, we are presenting a rare complication of organophosphate poisoning.

\section{Case Report}

A 75-year-old homemaker presented to our emergency department following deliberate self-harm consuming around $100 \mathrm{ml}$ chlorpyrifos along with small amount of kerosene. She was known to have systemic hypertension and was not on any treatment for the same. There was increased salivation, sweating, vomiting, diarrhea, and urination. She had pinpoint pupils and fasciculation over chest, arms, and thighs. Pulse rate was 120 beats/min and irregular. Rest of the examination was normal.

Hemoglobin was $15.5 \mathrm{~g} / \mathrm{dl}$, total count $12,000 / \mu 1$, and platelet count $1.8 \mathrm{lakh} / \mathrm{L}$. Urine routine, renal, liver, and thyroid functions were normal. Serum potassium was $2.8 \mathrm{mEq} / \mathrm{L}$. All other electrolytes were normal. Electrocardiogram showed rate 140/min, electrical alternans, multifocal ventricular ectopics, ventricular reentrant beats, ventricular couplets, and prolonged qT interval (corrected qT $=512 \mathrm{~ms}$ ). Echocardiogram was

\begin{tabular}{|l|l|}
\hline \multicolumn{3}{|c|}{ Access this article online } \\
\hline Quick Response Code: & Website: \\
& www.ijccm.org \\
\cline { 2 - 2 } & \\
\end{tabular}

normal. Arterial blood gas analysis showed normal anion gap metabolic acidosis. Transtubular potassium gradient was 6.85 , and urine analysis revealed inappropriately raised urinary $\mathrm{pH}$ (7.5) with positive urine anion gap all suggestive of distal renal tubular acidosis.

She was treated with decontamination, atropine, and potassium supplements. Initially, potassium values did not improve despite intravenous correction. However, her cholinergic symptoms subsided, and potassium values started improving once atropinization was attained. Her repeated electrocardiogram 2 days later showed sinus rhythm with occasional multifocal ventricular ectopics. She was reviewed 2 weeks later. Blood gas analysis, urine potassium excretion, urine $\mathrm{pH}$, and urine anion gap done were normal with serum potassium $4.5 \mathrm{mEq} / \mathrm{L}$. Electrocardiogram showed no ectopics, all proving the above episode a transient one.

\section{Discussion}

Organophosphate poisoning is a medical emergency. They act in central and peripheral nervous system mainly in

Address for correspondence: Dr. Ram Narayan, Department of General Medicine, MES Medical College, Perinthalmanna - 679338 , Kerala, India. E-mail: drramnarayan1283@gmail.com

This is an open access article distributed under the terms of the Creative Commons Attribution-NonCommercial-ShareAlike 3.0 License, which allows others to remix, tweak, and build upon the work non-commercially, as long as the author is credited and the new creations are licensed under the identical terms.

For reprints contact: reprints@medknow.com

How to cite this article: Narayan R, Abdulla MC, Alungal J. Transient distal renal tubular acidosis in organophosphate poisoning. Indian J Crit Care Med 2017;21:170-1. 
neuromuscular junction. They inhibit acetylcholinesterase enzyme reversibly as well as irreversibly producing excess of acetylcholine in neuromuscular junction. Hence, usually, clinical presentation of organophosphates includes excessive muscarinic symptoms such as increased salivation, lacrimation, urination, diarrhea, gastrointestinal cramps, emesis, and nicotinic symptoms such as tachycardia, hypertension, mydriasis, fasciculation, and weakness. Rarely may they present with intermediate syndrome or delayed polyneuropathy. Rare reported presentations of organophosphate presentation include pancreatitis and hepatitis. ${ }^{[1]}$

Our patient had ventricular arrhythmias at the time of admission which is not common. Presentation of cardiac toxicities of organophosphates may be of three types. ${ }^{[2]}$ It may be intense sympathetic activity due to nicotinic effect producing tachycardia and hypertension or muscarinic activity producing bradycardia and hypotension. Third case, they may present with polymorphic ventricular tachycardia with prolonged qT in early phase of toxicity which is attributed to rise in free fatty acid levels by some authors. ${ }^{[3]}$ However, in all studies, echocardiogram was normal showing no permanent damage to heart. Cardiac injury is a strong predictor of mortality in organophosphate poisoning, ${ }^{[4]}$ and direct myocardial injury is maximum in acute early phase of severe organophosphate poisoning. ${ }^{[5]}$ Our patient also had severe hypokalemia. Potassium value if $<3 \mathrm{mEq} / \mathrm{L}$ is known to present with multifocal ventricular ectopics, ventricular reentrant beats, ventricular couplets, and prolonged qT interval. ${ }^{\left[{ }^{[6]}\right.}$ In our patient, cardiac arrhythmias may be due to either organophosphate poisoning or hypokalemia or both combined.

Renal complications due to organophosphate poisoning are unheard of. Our patient had severe hypokalemia which was evaluated and detected to be due to distal renal tubular acidosis. Transient distal tubular acidosis may be seen in paraproteinemia, medullary sponge kidney, nephrocalcinosis, obstructive uropathy, and autoimmune diseases. ${ }^{[7]}$ There was one reported case where distal tubular acidosis was detected with accidental kerosene ingestion. ${ }^{[8]}$ However, that patient also had concomitant ingestion of metformin in a high dose which produced lactic acidosis and acute renal failure. However, in our case, very minimal amount of kerosene has been ingested which cannot explain her tubular acidosis. Hence, the same may be attributed to organophosphates itself as it completely improved after atropinization. Toluene poisoning presenting with transient distal renal tubular acidosis was reported, which has been attributed to impaired active hydrogen ion transport and hydrogen ion back diffusion. ${ }^{[9]}$ The same mechanism may be the cause of transient distal renal tubular acidosis due to organophosphate poisoning also though conclusive proof is yet to be availed.

\section{ConcLusion}

Organophosphate poisoning is very common in our day-to-day practice. Hence, it is better to know about all atypical presentations and expected complications of its toxicity. Although neurological complications are quite well described, many others such as pancreatitis, hepatitis, and cardiac toxicities are seldom accounted. We are presenting this case just to open up possibility of a rare complication of organophosphate poisoning, distal renal tubular acidosis which should be thought of in the presence of persistent hypokalemia refractory to treatment.

\section{Financial support and sponsorship}

Nil.

\section{Conflicts of interest}

There are no conflicts of interest.

\section{RefEREnCES}

1. Chowdhury FR, Bari MS, Alam MM, Rahman MM, Bhattacharjee B, Qayyum JA, et al. Organophosphate poisoning presenting with muscular weakness and abdominal pain - A case report. BMC Res Notes 2014;7:140.

2. Chacko J, Elangovan A. Late onset, prolonged asystole following organophosphate poisoning: A case report. J Med Toxicol 2010;6:311-4.

3. Kiss Z, Fazekas T. Arrhythmias in organophosphate poisonings. Acta Cardiol 1979;34:323-30.

4. Aghabiklooei A, Mostafazadeh B, Farzaneh E, Morteza A. Does organophosphate poisoning cause cardiac injury? Pak J Pharm Sci 2013;26:1247-50.

5. Cha YS, Kim H, Go J, Kim TH, Kim OH, Cha KC, et al. Features of myocardial injury in severe organophosphate poisoning. Clin Toxicol (Phila) 2014;52:873-9.

6. Helfant RH. Hypokalemia and arrhythmias. Am J Med 1986;80:13-22.

7. Chan JC, Alon U. Tubular disorders of acid-base and phosphate metabolism. Nephron 1985;40:257-79.

8. Rathnapala A, Matthias T, Jayasinghe S. Severe lactic acidosis and acute renal failure following ingestion of metformin and kerosene oil: A case report. J Med Case Rep 2012;6:18.

9. Batlle DC, Sabatini S, Kurtzman NA. On the mechanism of toluene-induced renal tubular acidosis. Nephron 1988;49:210-8. 